\title{
Analysis of Livelihood Diversification to Food Security among Rural Households in Ndhiwa Sub County, Homa Bay County, Kenya
}

\author{
Jedidah Kandagor, Dr. Kefa O. Nyandoro* \\ School of Social Sciences, Mount Kenya University, Thika, Kenya \\ *Corresponding author: kjedidah88@yahoo.com
}

Received June 02, 2018; Revised August 08, 2018; Accepted September 03, 2018

\begin{abstract}
Diversifying livelihoods has over the last two decades been identified as an important theme particularly in poverty reduction agenda. Although statistics show that there is enough food for everyone, close to 795 million of the world's population is still food insecure. Poverty level in Homa Bay county stands at $48 \%$ compared to the National poverty indicator at $45 \%$. The purpose of this study was to assess livelihood diversification to food security among rural households in Ndhiwa Sub County, Homa Bay County, Kenya. The target population was 43,214 persons and sample size was 400 households. Data was collected using questionnaires and Focus Group Discussion Guide was also used to gather information to triangulate data from the target respondents. Four Focus Group discussions were conducted from two administrative wards and each FGD comprised of 10 members/respondents. The study further used Key Informant Interviews among six respondents who were well knowledgeable and experts in agricultural practices at the Sub County and County level. Forty two per cent of the respondent pointed out that diversification had increased food availability while $31.9 \%$ pointed out an increase in access to food. This indicates diversification contributed significantly on household food security. Secondly, $85.6 \%$ responded having not received required livelihood extension services. The study found out a significant difference $(\mathrm{p}<0.05), \mathrm{p}=0.000$ in the amount in stock by farmers before and after beginning diversification. Households deployed mixed farming, storing cereal in stores, timely planting, leasing of land, dietary change, proper farming practices, and carrying out irrigation as vulnerability measures. The study concluded that diversification contributed to food security of farmers by enhancing their access to staple food. It further concluded that most serious challenges faced by farmers in improving food security through diversification were small pieces of land and inadequate capital.
\end{abstract}

Keywords: coping strategies, diversification, food security, livelihood

Cite This Article: Jedidah Kandagor, and Dr. Kefa O. Nyandoro, "An Analysis of Livelihood Diversification to Food Security among Rural Households in Ndhiwa Sub County, Homa Bay County, Kenya." Journal of Food Security, vol. 6, no. 2 (2018): 90-98. doi: 10.12691/jfs-6-2-6.

\section{Introduction}

At a global level, food security and response discussions can be traced back to the 1943 Hot Springs Conference on Food and Agriculture, the establishment of Food and Agriculture Organization (FAO) in 1945 and the Universal declaration of access to adequate food as a human right in 1948 [1]. According to estimates by FAO, there are 795 million undernourished people globally with the vast majority living in the developing world .Out of the affected population, three-quarters of the population live in rural areas including those displaced by civil conflicts and those living in dry lands with inadequate rainfall for crop production [2].

According to [3], poverty and food security are increasingly Africanized. A staggering 234 million people are food insecure in Sub-Saharan Africa, which is 5 million less than the figure for the entire continent. One in every five persons goes to bed hungry. The governments need to step-up efforts to end hunger within the region [1]. As per [4], low political commitment by Governments of SubSaharan Africa need to create an enabling environment for addressing food insecurities.

For most Sub-Saharan Africa countries, public spending on agricultural research is less than 10 percent, which inevitably translates into low agricultural production [5] . For example, an assessment of how food security policies were incorporated into recent poverty reduction efforts revealed that only a half of this number had actually prioritized food security concerns. Efforts at attaining the Comprehensive Africa Agriculture Development Program targets under Africa Union's initiative have been slow. Even for those that have mainstreamed food security policies into their broader poverty reduction frameworks, they remain disjointed and lack coherence; affirming the 'policy failures' argument put forward by [3].

In a meta-analysis of 49 case studies within the Southern Africa sub-region, [6] finds that food insecurity is the "outcome of the interaction between environmental 
stressors, and socio-economic conditions, over various time scales." [6], through a combination of direct and indirect indicators, found that constraints to food access were significant determinants than the decline in food production at the micro-level.

The Kenya Food Security Steering Group (KFSSG) increased the projected number of people requiring emergency food assistance between September 2009 and February 2010 to 3.8 million individuals, representing a 32 percent increase since February 2009. Additionally 2.5 million chronically food-insecure individuals located in urban areas [7]. The reasons for increasing food insecurity are varied. According to [7], the causes of food insecurity in Kenya include low agricultural productivity, inadequate access to productive assets (land and capital), inadequate access to appropriate technologies by farmers, effects of global trade and slow reform process.

Over the years, the Kenyan Government has initiated food security projects such as Njaa Marufuku Kenya (NMK) to address food insecurity. The aim of rural livelihood diversification is to reduce risk which is related to agricultural activity and to supplement farm income [7]. In Kenya, the strategic objective is to cut the food insecure people by 600,000 annually [8]. One of the strategic plans for achieving the objective is identification and up-scaling of successful pilot projects [9]. Food insecurity in Kenya is concentrated in the rural areas. In 2008, an estimated 1.3 million people in rural areas and 3.5-4 million in urban areas were food insecure. Approximately 100,000 more children have become malnourished as a result of the food crisis [10]. At national level, the problem is reflected in: growing dependence on food imports-Kenya has been getting increasingly dependent on food imports [11].

Homa Bay County is characterized by a rapidly growing population, $92 \%$ of the inhabitants living in the rural areas with a high population density, falling food production as a result of climate change, over reliance on rain fed agriculture and dependence on long term cash crop such as sugarcane. These combined effects of crop failure, due to climate change and rapid population growth are increasing food insecurity and poverty levels in the county hence need to examine role of livelihood diversification. It is noted that Homa Bay households do not have enough food to meet their household needs throughout the year [12]. Sixty three per cent of the total land is used for farming, however $50 \%$ of the households suffer from food poverty every six months of the year [8]. Household Food insecurity peaks between July and August and between December and March when harvested stocks have been depleted.

[13] argue that the concept of livelihood diversification evolved as a response to the failure of International Monetary Fund and World Bank's Structural Adjustment Programmes to provide the catalyst for increased agricultural production in most developing countries. [14] defines livelihood diversification as the development of a wide income earning portfolio to cover all types of shocks or stress jointly or the strategy may involve focusing on developing responses to handle a particular type of common stock or stress through a well-developed coping mechanisms. [15] Considers livelihood diversification as comprising of two components; First, it's perceived as a progressive development tool that spurs economic growth within the rural economy; Secondly, livelihood diversification is a mere stop-gap for fostering secured livelihoods during periods of hardships. There exist a number of factors that propels households to diversify means of livelihoods. [16] points out to risk management as the basic reason for households' engagement in multiple livelihoods. Diversification is more of a reactive strategy than a proactive one, on the other hand [15] observes that beliefs, risk, discontinuity, complementarities and flexibility form the four core economic reasons that may propel an individual or household to diversify its livelihood set.

Households diversify their livelihood because of two reasons one is in order to cope with the risk occurring by force and the other is households diversify by their choice for different reasons which may not necessarily force them to diversify. Referring to the food security crises that hit southern African countries between 2001 and 2003, [13] found out that farm households with limited degree of livelihood diversification were the hardest hit. Separate studies [17] showed a strong linkage between non-farm diversification and drought in Burkina Faso. Using households shares of time spent on non-farm employments, [18] found a linkage between diversification and household consumption levels and poverty reduction in the Mekong River Delta of Vietnam. [16] Reveal strong correlation between "nonfarm income shares" with household welfare in Ethiopia. Likewise in Peri-urban Tanzania, diversification displays a positive relationship with food consumption. [19] Using propensity score matching techniques to do a study in Savelugu-Nanton district of Northern Ghana and found out that farm households that engaged in non-farm work were more food secure than households relying solely on farming as a livelihood source. Similarly, results from a study of farm households in the Kwara State of Nigeria by [20] revealed that non-farm income affects household calorie and micronutrient supply, dietary quality, and child's development. In examining gender effects, [19] found out that in Ghana, diversification helps female-headed households to escape dangers of chronic poverty and food insecurity. The evidence presented indicates the imperativeness of diversification for food security and household welfare.

However, other studies have revealed the contrary. In a study by [21] to find out factors influencing food security status of farming households in the forest belt of the central region of Ghana, it was revealed that household income, dependency ratio, access to credit and quantity of households' own produce were significant factors while engagement in non-agricultural activities showed no significant effect. This finding is in contravention to the purported impact of livelihood diversification on household food security. Also, [22] found out in a study in Southwest Nigeria that livelihood diversification had an insignificant effect on household food poverty. According to [13], coping strategies comprises tactics for maintaining consumption when confronted by disaster, such as drawing down on savings, using up food stocks, gifts from relatives, community transfers, sales of livestock, other asset sales, and so on

Sustainable Livelihoods Approach has inspired a new form of thinking, particularly regarding how development ought to be structured and organized. Following the failures of past development approaches such as the modernization theory to significantly eradicate poverty, 
which at the time was virtually a rural phenomenon; new thoughts on how to approach the challenge were sought [23]. The Department for International Development (DFID) Guidance Sheets describes Sustainable Livelihood Approach (SLA) as 'people-centered', in that the making of policy is based on understanding the realities of struggle of poor people themselves on the principle of their participation in determining priorities for practical intervention. Practically, the concept has been applied in a variety of development themes including food security [24], this is due to the fact that food is considered a fundamental component of people's livelihoods. The 'contextual and long-term perspective' of SLA and its emphasis on 'household assets' provide a practical guide for analyzing household food security as it brings to the fore issues of 'vulnerability, sustainability and coping strategies'. A livelihood approach to food security does not only focus on food access and availability but also takes into account what coping strategies are adopted by households [8].

\section{Materials and Methods}

\subsection{Target Population \& Location of the Study}

This study was conducted in Ndhiwa Sub County, an administrative unit of Homa Bay County, Kenya. According to the Kenya National Bureau of Statistics (2009), the Sub County covers $3,183.3 \mathrm{sq} \mathrm{km}$ with an approximate population of 200,082 people. The study targeted a population of 43,214 persons in Ndhiwa Sub County which is one of the administrative units of Homabay County. This County is situated in Nyanza, Kenya and its geographical coordinates are $0^{\circ} 44^{\prime}$ 0" South, 34 22' 0" East. Ndhiwa Sub County being one of the six sub counties in Homa Bay County. Major subsistence crops include maize, potatoes, millet and beans. Other economic activities include: tourism, trade, bee keeping, pastoralism and poultry keeping. The sub county has seven administrative wards: Kanyadoto, Kanyikela, Kabouch North, Kabuoch South/Pala, KanyamwaKologi and Kanyamwa Kosewe headed Ward Administrators

\subsection{Sampling Procedures and Techniques}

In this study, random sampling procedure was used to select six administrative wards where the study was conducted covering; Kanyadoto, Kanyikela, Kabouch North, Kabuoch South/Pala, Kanyamwa Kologi and Kanyamwa Kosewe. This method being a probability sampling method was not prone to biasness by the researcher. Probability proportionate to size was used to sample households to be interviewed from each administrative ward. The researcher further used simple random sampling to select specific number of households from each administrative ward.

\subsection{Sample Size}

Mugenda \& Mugenda (1999) defines a sample as a group or sub-group with similar characteristics selected to represent a given population. For this study, the sample size was arrived at by employing Yamane simplified formula to calculate the sample with $95 \%$ confidence level.

$$
\mathrm{n}=\mathrm{N} / 1+\mathrm{N}(\mathrm{e})^{2}
$$

Where:

$\mathrm{n}=$ sample size required

$\mathrm{N}=$ number of people in the population

$\mathrm{e}=$ allowable error $(\%)$.

Taking the population size as 43, 214 and allowable error as 0.05 , then the sample size becomes:

$$
\begin{aligned}
& \mathrm{n}=43,214 / 1+43,214(0.05)^{2} \\
& \mathrm{n}=43214 / 1+43,214(0.0025) \\
& \mathrm{n}=399.99 \\
& \mathrm{n}=400 .
\end{aligned}
$$

\subsection{Research Instruments}

Questionnaires were administered to household heads. The questionnaire comprised of closed-ended questions and a few open ended questions, closed ended questions were included because they were easier to administer and analyze. Open ended questions were included because they allowed the respondents to respond to questions in their own words and provide more detail on the study. Focus Group Discussion (FGD) Guide was used to gather information to triangulate data from the target respondents. Four Focus Group discussions were conducted from two administrative wards from the six. In each ward two Focus Group discussions were conducted, one targeting male household heads only and another female household heads only. Each FGD comprised of 10 members.

Key Informant Interviews (KII) were administered among representatives from: Community Based Organization, community organized structures, farmers' cooperatives, Agro vets, Ministry of Social Services, Health and Agriculture, livestock, fish, irrigation and Cooperative Development. A total of six Key Informant Interviews were conducted. KII helped the researcher get wide range of information regarding the area of study.

\subsection{Pilot Testing}

Pretest was conducted to establish effectiveness of the tool and validate data during data collection. According to Mugenda and Mugenda (2003) a pretest sample should be between $1 \%$ to $10 \%$ depending on the sample size and in this study, a pretest sample of $10 \%$ of the sample size (400) was used. During the pretest 40 questionnaires were administered, I Key informant interview and 1 FGD were conducted in Kisumu county.

\subsection{Validity of Research Instruments}

The researcher jointly with Mount Kenya University supervisor reviewed study instruments to find out if they effectively and adequately addressed study objective and research questions.

\subsection{Data Collection Procedures}

Data collection was done at the household level. All the questionnaires were completed in the presence of the researcher and collected the same day after their 
completion. On-spot checks were done for completeness, omissions and commission errors. The errors found were corrected at the study site to reduce the recall bias. The respondents also got an opportunity to seek for clarification on responses that were not clear.

\subsection{Data Analysis Techniques}

After completion of the data collection exercise, all the questionnaires were adequately checked for data quality, edited for completeness and consistency, organized and analyzed. For analysis of closed-ended questions, Statistical Package for social sciences (SPSS version 20.0) was applied and data analysis was done by descriptive statistics and inferential statistics.

\subsection{Ethical Considerations}

Banister et al. (1994), states that ethical concerns must be part of the fundamental design of any research project. Important ethical concerns were taken into consideration during the study. The researcher Sought approval from Mount Kenya University, School of Graduate Studies in getting Ethical Clearance Certificate which facilitated acquisition of a Research Permit from National Council of Science and Technology. The purpose of the research was fully disclosed to respondents and confidentiality was assured and maintained by not linking responses to any name.

\section{Research Findings and Discussions}

\subsection{Contribution of Livelihood Diversification on Household Food Security}

From the responses, $314(92.9 \%)$ indicated that diversification had contributed to household food security while $24(7.1 \%)$ indicated otherwise. Households practicing diversification experienced fewer months of food deficit especially during drought season, maintained dietary intake as households' accessed variety of specific food groups and stabilized food intake in a day as compared to households that have no attempts of diversification. The findings of concur with [25] who found out that households that had higher diversification options had minimal vulnerability to food insecurity.

\subsection{Practicing of Diversification}

From the results, majority $263(70.13 \%)$ practiced diversification while $112(29.9 \%)$ did not practice diversification. They were further asked to indicate the period in which they had practiced diversification. The results show that $81(26.2 \%)$ had practiced diversification for 0-2 years, $107(34.6 \%), 67(21.7 \%)$ for 6-10 years while $54(7.5 \%)$ had practiced diversification for over 10 years. From the findings this is attributed by crop patterns, whereby farmers have preference to alternative crops with high value. The results indicate change towards economic environment, by embracing off farm activities while maintaining primary production activities. This finding is in agreement with [7] observations that the adoption of livelihood diversification by a household may be motivated by either increased vulnerability or being a deliberate effort by households to broaden their income streams for the purpose of accruing and investing in future.

\subsection{Livestock Kept}

The results indicate that the most common livestock kept by respondents were cattle, chicken, goats and sheep. From the findings, it was noted that cattle, goat and sheep were kept to cushion households against vulnerability i.e. they can be sold to source for school fees and to offset medical costs, whereas other kept livestock as a result of social factors such as payment of dowry and to entertain guests. The researcher, noted that livestock has not been commercialized main reason being limited grazing land among households. Others kept were ducks and pigs. The findings agree with [16] who argue that agricultural or farm income constitute incomes derived from the production or gathering of unprocessed crops, livestock, forest or fish products from natural resources. This is further supported by [13], [26] who point out that African households diversify their livelihood strategies by practicing on-farm (crop and livestock) and off-farm activities to mitigate risks inherent in unpredictable agro-climatic, political, and socio-economic circumstances.

\subsection{Amount of Food in Stock before and after Diversification}

The study sought to find the amount of food in stock before and after beginning of diversification.

Table 1. Amount of Stock before and after Diversification

\begin{tabular}{lccccr}
\hline & Sum of Squares & df & Mean Square & F & Sig. \\
\hline Between Groups & 807.340 & 18 & 44.852 & 81.880 & .000 \\
Within Groups & 164.882 & 301 & .548 & & \\
Total & 972.222 & 319 & & & \\
\hline
\end{tabular}

The results shows that there was a significant difference $(p<0.05)$ in the amount in stock by farmers before and after beginning diversification. This shows that diversification contributed to the food security of farmers by enhancing their access to staple food.

\subsection{Eating Times before and after Beginning of Diversification}

Respondents were further, asked to indicate the number of times they ate per day before beginning diversification. The results revealed that $46(12.8 \%)$ were eating once in a day, $163(45.4 \%)$ were eating twice in a day, $142(39.6 \%)$ were eating three times while $8(2.2 \%)$ were eating four times a day before diversification. Reasons contributing to households to having one or two meals per day include high food prices of the locally available food, high cost of primary production inputs hence households will tend to produce less food and household chores, that forces most household head to leave their homes to tend to other activities that lead to an increase in family income. This therefore, implies that most families will skip day time meals and concentrate on evening and morning meals. 
The results from the study also showed that after beginning diversification, $8(2.3 \%)$ were eating once, 85 $(24.1 \%)$ were eating twice, $151(42.8 \%)$ were eating thrice while $50(14.2 \%)$ were eating four times a day. From the results, a decrease is noted in those who were eating once before beginning diversification and those eating one after beginning diversification. This can be shown in Figure 1.

Pearson's correlation was used to find if there was a significant relationship between the number of eating times before beginning diversification and after beginning diversification. The results showed that there was a significant positive relationship $(p<0.05), p=0.000$ between the number of eating times before beginning of diversification and after beginning diversification. This points out a general increase in the number of eating times per day once farmers began practicing diversification. Similarly, descriptive statistics were used to establish the mean number of eating times before beginning diversification and after beginning diversification.

To establish if diversification had affected the number of month's households were experiencing serious food shortages, respondents were asked to indicate the number of months they faced serious food shortages before beginning diversification. The responses were summarized in Figure 1.

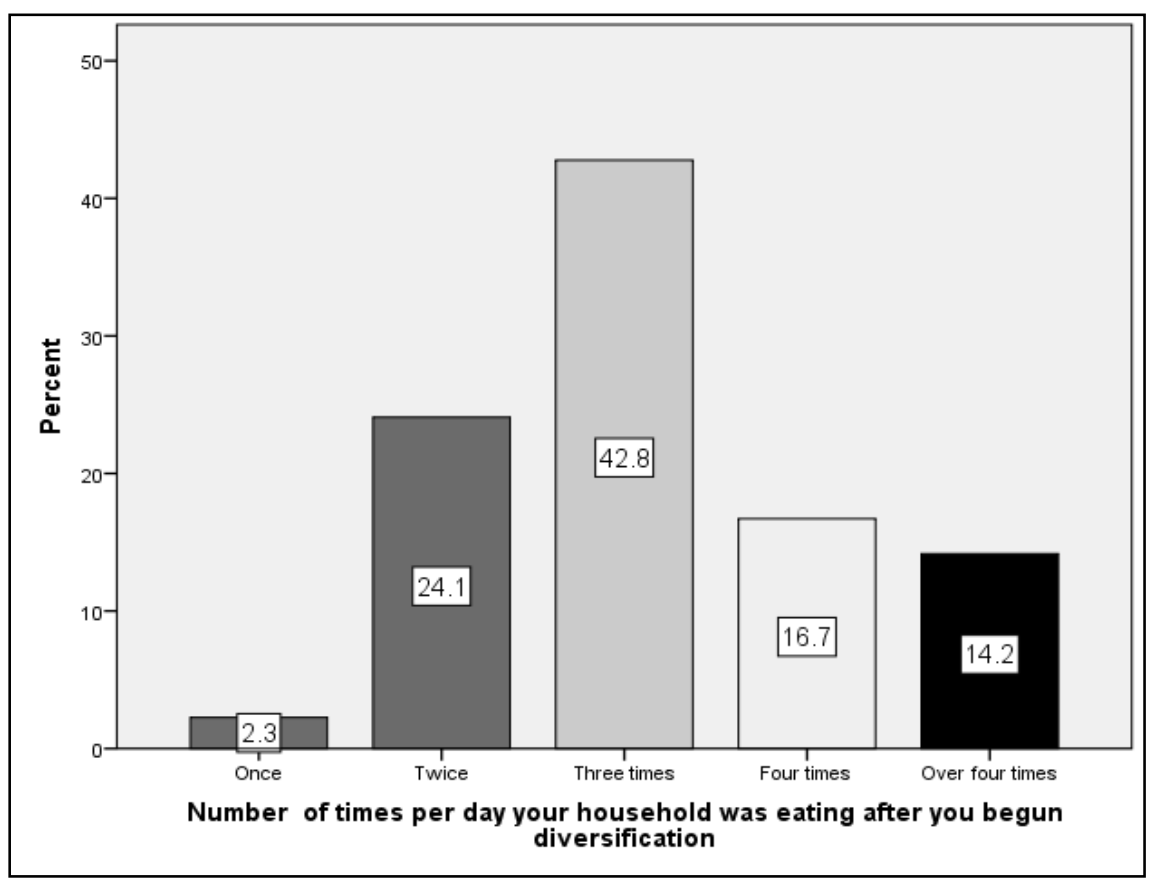

Figure 1. Number of Times per day of Eating after Diversification

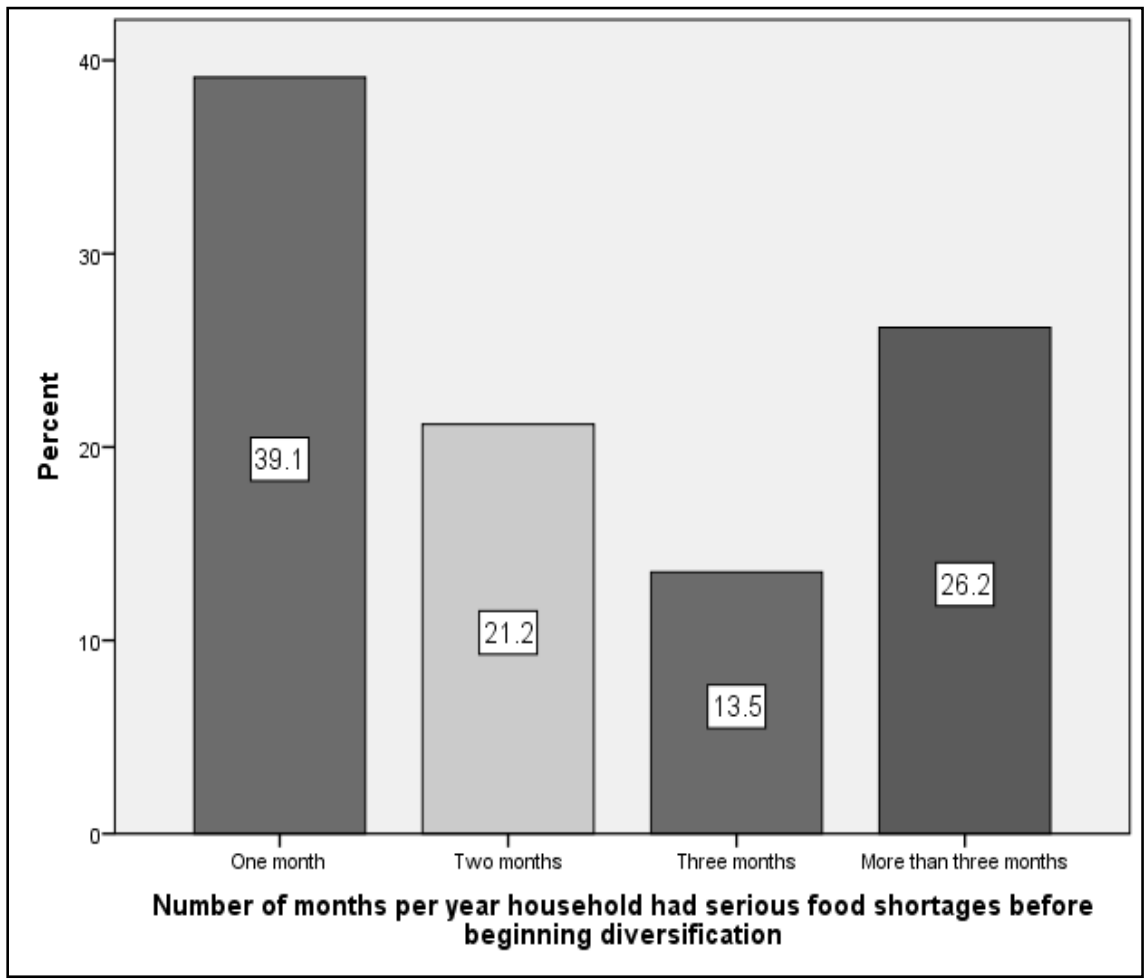

Figure 2. Number of Months per Year with Serious Food Shortages Before Diversification 
The results showed that $133(39.1 \%)$ indicated one month of food shortage, $72(21.2 \%)$ two months of food shortage, $46(13.5 \%)$ three months and $89(26.2 \%)$ indicated more than three months of serious food shortages before beginning diversification. Transition to harvesting season can be attributed to one month food shortage, while selling more than half of the harvested crops to meet other household needs leads to longer months of household food insecurity.

Respondents were further asked to indicate the number of months they faced serious food shortages after beginning diversification. The responses were summarized in Figure 2.

From the results, $141(41.5 \%)$ indicated one month, 109 (32.1\%) two months, $67(19.7 \%)$ three months and 23 $(6.8 \%)$ indicated more than three months of serious food shortages before beginning diversification. The results generally show a reduction in the number of months of serious food shortages after beginning diversification.

Pearson's correlation was used to find if there was a significant relationship between the months of serious food shortages before beginning diversification and after beginning diversification. The results showed that there was a significant $(p<0.05), p=0.000$ between the number of months of serious food shortages before beginning diversification and after beginning diversification. The results further indicated that there was a reduction in the number of months of serious food shortages from a mean of 2.2676 to 1.9176 . These points out that diversification contributed to a reduction in the number of months of serious food shortages.

Respondents who practiced diversification were finally asked to indicate how best they would describe diversification's contribution to household food security. From the results, majority pointed out that diversification had increased availability of food $(42.1 \%)$ and increased availability and access to food $(31.9 \%)$. This study is in agreement with [16] who contend that diversification points to risk management as the basic reason for households' engagement in multiple livelihoods.

\subsection{Diversity Score}

The study sought to determine the diversity score among respondents by asking them to indicate the foods they had eaten the previous day. Out of the 12 food types, the results were summarized in Table 2.

Table 2. Diversity Score

\begin{tabular}{ccc}
\hline Score & Frequency & Percent \\
\hline 2.00 & 18 & 4.8 \\
3.00 & 57 & 15.2 \\
4.00 & 64 & 17.1 \\
5.00 & 40 & 10.7 \\
6.00 & 32 & 8.5 \\
7.00 & 54 & 14.4 \\
8.00 & 94 & 25.1 \\
10.00 & 8 & 2.1 \\
11.00 & 8 & 2.1 \\
\hline Total & $\mathbf{3 7 5}$ & $\mathbf{1 0 0 . 0}$ \\
\hline
\end{tabular}

The data was categorized into the following rating in Figure 3

The results showed that majority of the respondents had a medium diversity score $(58.4 \%)$ followed by low diversity score $140(37.3 \%)$.Correlation analysis was carried out to establish if there was a significant relationship between practicing diversification and the diversification score. The results show that there was a significant relationship $(\mathrm{p}<0.05, \mathrm{p}=0.000)$ between practicing diversification and the diversity score.

Cross-tabulations were further carried out to ascertain the relationship between practicing diversification and diversification score. The results were summarized in Table 3 .

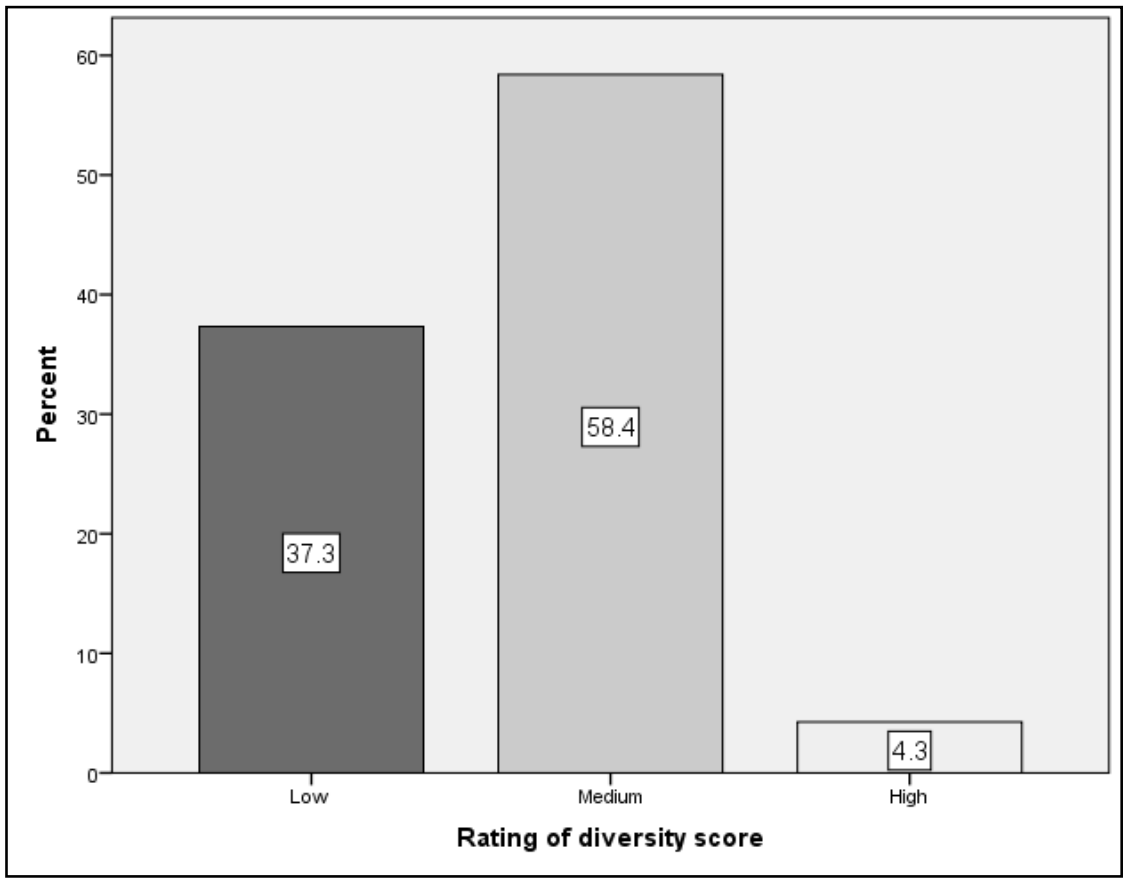

Figure 3. Rating of diversity score 
Table 3. Practicing of Diversification versus Rating of Diversity Score Cross tabulation

\begin{tabular}{lccccc}
\hline & & \multicolumn{3}{c}{ Rating of diversity score } & \multirow{2}{*}{ Total } \\
& & Low & Medium & High & \\
\hline Practicing of & Yes & 58 & 189 & 16 & 263 \\
diversification & No & 82 & 30 & 0 & 112 \\
Total & & 140 & 219 & 16 & 375 \\
\hline
\end{tabular}

From the results, all the $16(100 \%)$ farmers who had a high score were practicing diversification.

A chi square test of independence was also carried out on the data to establish if there were significant differences in the diversity scores between those who practiced diversification and those who did not. The results were summarized in Table 4.

Table 4. Chi square tests

\begin{tabular}{lccc}
\hline & Value & df & Asymp. Sig. (2-sided) \\
\hline Pearson Chi-Square & $89.215^{\text {a }}$ & 2 & .000 \\
Likelihood Ratio & 92.390 & 2 & .000 \\
Linear-by-Linear Association & 83.714 & 1 & .000 \\
N of Valid Cases & 375 & \\
\hline
\end{tabular}

The results also indicated that there was a significant relationship $(\mathrm{p}<0.05, \mathrm{p}=0.000)$ between practicing diversification and the diversity score.The results are in agreement with those of [9] whose study of urban farmers in Nairobi found out that households who diversified from wage employment to pursue farming as complementary income source were able to improve their food security levels.

\subsection{Challenges Faced in Improving Food Security through Diversification}

Respondents were asked to give the challenges faced in improving food security through diversification. The responses were summarized in Table 5.

Table 5. Challenges faced in improving food security through diversification

\begin{tabular}{lcc}
\hline Change & Frequency & Percent \\
\hline Small piece of land & 104 & 30.8 \\
Inadequate capital & 69 & 20.4 \\
Lack of skills & 56 & 16.6 \\
Small piece of land and inadequate capital & 45 & 13.3 \\
Small piece of land and lack of skills & 48 & 14.2 \\
Inadequate capital and lack of skills & 16 & 4.7 \\
\hline Total & $\mathbf{3 3 8}$ & $\mathbf{1 0 0 . 0}$ \\
\hline
\end{tabular}

From the results, the most serious challenges faced by farmers in improving food security through diversification were small pieces of land as a result of customary rights, where land had to be divided leaving the land inadequate for food production. On the other hand, lack of access to capital for adequate food production, commercialization of food production and establishment of food production. Others cited were lack of skills and drought. The findings concur with [27] who found out that small scale farmers from rural areas faced several challenges among them inadequate access to productive resources, price of inputs such as herbicides and fertilizers, market access and cost of transport.

The respondents were asked whether they received any extension services. The results revealed that only 50 $(14.4 \%)$ had received extension service while the majority $298(85.6 \%)$ had not received any support to strengthen their livelihood activities. This is attributed mainly by extension officers reaching out to organized groups (household members belong to organized groups) for capacity building and advisory services as compared to reaching out to stand alone household heads. These groups are at par with new opportunities and trends, therefore advantaged. This finding is in agreement with [28] who observed that initiatives by international NGOs such as the International Fund for Agricultural Development (IFAD), with support from Governments have sought to create the enabling environment in curtailing some of the challenges rural households face in venturing into such enterprises.

For those who had received service, they were asked to indicate the support that they had received. The results show that the support received included financial, advice, training, farm inputs, free goats and free vaccination which facilitated uptake of household food security.

The results reveal that $8(40.0 \%)$ had received support from Agricultural extension officers, $2(10 \%)$ from county governments, $5(25.0 \%)$ from NGOs, CBOs or SHG while $5(25.0 \%)$ had received support from well-wishers. Amidst of embracing new approach in Agricultural extension, the Government of Kenya is embracing E-extension services and E- Clinics which curbs the number of hours an extension officer travels to offer services to one particular household. Using a mobile phone has made it easier for household to attend $\mathrm{E}$ agricultural clinics where they receive advisory services. This poses a disadvantage to household's heads with no mobile phones.

\subsection{Strategies Put in Place to Ensure that the Household is Food Secure}

The study sought to determine the coping strategies by households in ensuring that their households are food secure. Respondents were asked to state the coping mechanisms in ensuring that household is food secure. From the results, the coping mechanisms in rank order were: diversification; practicing mixed farming; storing cereal in stores/ good storage; early planting/ timely planting; leasing of land; dietary change; selling assets; proper farming practices; agro business; carrying out irrigation; purchasing other food stuffs; venturing into business; getting loans to buy farm inputs; increased farm work; use of fertilizers; and use of certified seeds. The results are in agreement with those of a study by [29] who found out that most households replied in the affirmation about relying on less preferred and less expensive foods. This included consumption of low grades (or cheaper quality) of wheat, broken rice, and cheap cuts of meat like feet, intestines or upper part of skin. It further established that seventeen percent households reduced numbers of 
meals eaten in a day.Some households sold their assets like furniture, jewelry or utensils when they needed to buy food. However, such cases were very few.

\section{Conclusion}

Drawing from the findings, the research derived the following conclusion; Diversification facilitates increased food security among households by increasing the availability and accessibility to food. This translates to a reduction in the number of months of serious food shortages after beginning diversification, an increase in eating times per day; a decrease in the period of food shortages and an increase in the diversity of foods accessed. The study established that most farmers faced many problems in their endeavor to improve their food security through diversification. They included small pieces of land, inadequate capital, and lack of skills, drought and poor access to extension services. The coping strategies on respondents' vulnerability to food security were diversification, practicing mixed farming, storing cereal in stores/ good storage, early planting/ timely planting, leasing of land, dietary change (eating less expensive foods), selling assets, proper farming practices, agro business, carrying out irrigation, purchasing other food stuffs, doing business, getting loans to buy farm inputs increased farm work, use of fertilizers; and use of certified seeds.

\section{Recommendations}

The following recommendations were made based on the findings and the conclusions of the study: There is therefore need for the government (Central and County) to encourage farmers to carry out diversification and give them the necessary support to enhance diversification. The County government should employ more extension officers to be able to meet the extension needs of farmers especially in the rural areas where most household cannot be able to use E-agricultural services. This would include trainings on how to maximize the use of their pieces of land however small they might be. Farmers need to be encouraged to practice irrigation farming instead of depending on rain-fed agriculture so that they are not adversely affected during droughts.

\section{Suggestions for Further Research}

The study recommends further research on;

i) Contribution of Village Savings and Loaning Association and other micro financial institutions on household food security among rural households in Ndhiwa Sub County. Twenty per cent of respondents cited lack of capital as a challenges in the attempt of diversifying of enhanced household food security.

ii) Livelihood diversification among rural households across the other 5 sub counties within Homabay County to triangulate the findings.

\section{References}

[1] "Joint FAO/WHO activities on risk assessment of microbiological hazards in foods call for data and experts on public health risk of histamine and other biogenic amines from fish and fishery products," 2011.

[2] Kennedy, G., Nantel, G. and Shetty, P, "Globalization of food systems in developing countries: impact on food security and nutrition," 2004

[3] Maxwell, S, "Food security: a post-modern perspective," Food Policy, vol. 21, no. 2, pp. 155-170, May 1996.

[4] Tobin, J.C, Hunger efforts and food security. Nova Science Publishers, 2009

[5] Young, E.M, "Globalization and food security: novel questions in a novel context?," Prog. Dev. Stud., vol. 4, no. 1, pp. 1-21, Jan. 2004

[6] Misselhorn, A.A, "What drives food insecurity in southern Africa? a meta-analysis of household economy studies," Glob. Environ. Chang., vol. 15, no. 1, pp. 33-43, Apr. 2005.

[7] Muthoni Thuo, C, "The Influence of Enterprise Diversification on Household Food Security Among Small-scale Sugarcane Farmers: A Case Study of Muhoroni Division, Nyando District, Kenya," J. Agric. Educ. Ext., vol. 17, no. 3, pp. 223-238, Jun. 2011.

[8] Young, H., Jaspars, S., Brown, R., Frize, J. and Khogali, H, "Food-security assessments in emergencies: a livelihoods approach," 2001.

[9] Njogu, E.W, "Household Food Security Among Urban Farmers in Nairobi, Kenya," pp. 39-52, May 2012.

[10] Hoffman, S, "Save the children," Nature, vol. 430, no. 7002, pp. 940-941, Aug. 2004

[11] Odhiambo, W., Nyangito, H.O. and J. Nzuma, "Sources and Determinants of Agricultural Growth and Productivity in Kenya," 2004.

[12] D. Social Aspects of HIV/AIDS Research Alliance and J. South African Medical Association (1998- ). Health and Medical Publishing Group, SAHARA-J: journal of social aspects of HIV/AIDS., vol. 6, no. 4. Taylor \& Francis, 2009.

[13] Ellis, F, "The Determinants of Rural Livelihood Diversification in Developing Countries," J. Agric. Econ., vol. 51, no. 2, pp. 289-302, Nov. 2008.

[14] Scoones, I, "Sustainable Rural Livelihoods: A Framework for Analysis," 1998.

[15] Start, D. and Johnson, C, "Livelihood Options? The Political Economy of Access, Opportunity and Diversification," 2004.

[16] Barrett, C., Reardon, T. and Webb, P, "Nonfarm income diversification and household livelihood strategies in rural Africa: concepts, dynamics, and policy implications," Food Policy, vol. 26, no. 4, pp. 315-331, Aug. 2001.

[17] Barrett, C.B, "Chapter 40 Food security and food assistance programs," Handb. Agric. Econ., vol. 2, pp. 2103-2190, Jan. 2002.

[18] Nghiem, L.T, Activity and Income Diversification: Trends, Determinants and Effects on Poverty Reduction. The Case of the Mekong River. 2010.

[19] Owusu, V., Abdulai, A. and Abdul-Rahman, S, "Non-farm work and food security among farm households in Northern Ghana," Food Policy, vol. 36, no. 2, pp. 108-118, Apr. 2011.

[20] Babatunde, R.O. and Qaim, M, "Impact of off-farm income on food security and nutrition in Nigeria," Food Policy, vol. 35, no. 4, pp. 303-311, Aug. 2010.

[21] K. J. K.M., S. D. M., and A. D. P.K., "Analysis of food security status of farming households in the forest Belt of the Central Region of Ghana," Russ. J. Agric. Socio-Economic Sci., vol. 13, no. 1,2013

[22] Awotide1, O., Kehinde2andpetero, A. and Agbola3, "Poverty and rurallivelihood diver sification among farming households in southwest Nigeria," J. Food , Agric. Environ., vol. 88, no. 11, pp. 367-371, 2010.

[23] Ashley, C. and Carney, D, "Sustainable livelihoods: Lessons from early experience issues DFID Department for International Development."

[24] Burchi, F. and De Muro, P "A Human Development and Capability Approach to Food Security: Conceptual Framework and Informational Basis," 2012. 
[25] Hanazaki, N., Berkes, F., Seixas, C.S. and Peroni, N, "Livelihood Diversity, Food Security and Resilience among the Caiçara of Coastal Brazil," Hum. Ecol., vol. 41, no. 1, pp. 153-164, Feb. 2013.

[26] Bryceson, D.F, "African rural labour, income diversification \&amp; livelihood approaches: a long term development perspective," Rev. Afr. Polit. Econ., vol. 26, no. 80, pp. 171-189, Jun. 1999.

[27] Azam, J.P. and Besley, T, "Peasant supply response under rationing: The role of the food market," Eur. J. Polit. Econ., vol. 7, no. 3 , pp. 331-343, Oct. 1991
[28] Warren, P, "LSP Working Paper 4 Livelihoods Diversification and Enterprise Development Sub-Programme FOOD AND AGRICULTURE ORGANIZATION OF THE UNITED NATIONS Livelihood Support Programme (LSP) An interdepartmental programme for Improving support for enhancing livelihoods of the rural poor. Livelihoods Diversification and Enterprise Development An Initial Exploration of Concepts and Issues," 2002.

[29] Kushel, M.B, Gupta, R., Gee, L. and Haas, J.S, "Housing instability and food insecurity as barriers to health care among low-income americans," J. Gen. Intern. Med., vol. 21, no. 1, pp. 71-77, Jan. 2006. 